\title{
ARTÍCULO
}

\section{Re-ensamblando los vínculos de la ingeniería y la sociedad}

\author{
Reina-Rozo, Juan David*, Gaitán-Albarracín, Nicolás ${ }^{\circ}$ y Acero, Andrés $\dagger$ \\ * Universidad Nacional de Colombia, Sede Bogotá, Departamento de Ingeniería de Sistemas e \\ Industrial,jdreinar@unal.edu.co \\ - Universidad Nacional de Colombia, Sede Bogotá, Departamento de Ingeniería de Sistemas e \\ Industrial, PEAMA Sumapaz, ngaitana@unal.edu.co \\ $\dagger$ Universidad de los Andes, Departamento de Ingeniería Industrial, \\ ae.acero539@uniandes.edu.co
}

\section{UN PRIMER PASO PARA VISIBILIZAR ESTAS RELACIONES}

Esta primera edición de la Revista Internacional de Ingeniería, Justicia Social y Paz -RIIJSP- en su versión en español buscar generar una nueva plataforma de divulgación y comunicación científica alrededor de las interacciones desde una visión plural de la Ingeniería, la Justicia Social y la Paz, áreas, que quizás, desde una perspectiva tradicional de la academia no tienen una relación directa y de interdependencia. Sin embargo, desde esta revista defendemos y propiciamos un encuentro diverso que nutra nuevos diálogos, conversaciones, discusiones y acciones alrededor del rol social de la ingeniería y, por supuesto, de la ciencia en su conjunto.

Esta aventura de crear la versión en español de la revista se da en un contexto histórico de la disminución del gasto en ciencia y tecnología en Latinoamérica, la amenaza de la ciencia por parte del surgimiento de la mal llamada pos-verdad, la emergencia y permanencia de conflictos en los diversos rincones del planeta y, finalmente, la presión por parte de intereses económicos y políticos a las luchas por la justicia social y ambiental a nivel local. Es en este contexto, particularmente en el mundo de habla hispana, donde vemos que es necesario crear nuevos espacios que permitan compartir el conocimiento y las experiencias que se tejen entre la Ingeniería, la Justicia Social y la Paz.

Ahora bien, este camino se viene recorriendo hace años y varias personas han hecho parte del él. Esta revista nace en el seno de la Red de Ingeniería, Justicia Social y Paz (Engineering, Social 
Justice and Peace Network por sus siglas en inglés), que desde el año 2010 se viene reuniendo anualmente. Esta red tiene por objeto imaginar y practicar la ingeniería de manera que se extienda la justicia social y la paz en el mundo. Este compromiso se manifiesta en dos áreas principales: En primer lugar, al comprender cómo se construyen conjuntamente la tecnología y la sociedad, se comprometen a identificar y desmantelar los casos específicos de injusticia relacionados con la ingeniería y la tecnología. En segundo lugar, en colaboración con grupos comunitarios que se enfrentan a estructuras específicas de injusticia, se comprometen a idear y desarrollar tecnologías y otras soluciones de ingeniería (ampliamente concebidas) para los problemas a los que se enfrentan (ESJP Network, 2018).

Varios de los miembros fundadores provienen de países donde su lengua oficial es el español, reconociendo que en América Latina tenemos más de 300 lenguas de los pueblos originarios, así que ha habido un interés implícito de poder comunicarse con audiencias en el sur global. En este sentido, la red tuvo su primera reunión en Bogotá en el año 2011 convirtiéndose en un punto de inflexión donde diversas personas que no hablaban inglés pudieron participar de esta iniciativa. A partir de este primer encuentro, el diálogo se fortaleció entre los diversos miembros con el fin de seguir trabajando colectivamente. Siguiendo lo realizado en Bogotá, se realizaron encuentros en Buenos Aires en 2014 y en Puerto Rico en 2016 donde la comunidad de habla hispana pudo participar. Finalmente, en la última reunión de la Red llevada a cabo en el mes de enero de 2018 en San Diego en Estados Unidos, se decide la creación de la versión en Español de la revista para una audiencia de 650 millones de personas en más de una veintena de países. Esta nueva versión en español parte de la necesidad de nuevos medios para la divulgación científica en momentos en que, por las dinámicas de la academia global, se busca solo participar en publicaciones de habla inglesa, en su mayoría con acceso restringido al conocimiento y orientadas a audiencias científicas, más no a la sociedad en su conjunto quien es la realmente afectada o beneficiada por nuestros desarrollos tecnológicos.

Por esto, nuestra revista plantea la prioridad ser una más de las iniciativas por la ciencia abierta en la región, otra más que se une a un creciente número de organizaciones y medios por la liberación del conocimiento en América Latina. En este sentido, nos adherimos a la Declaración de Panamá de la Ciencia Abierta (Karisma, 2018), en la cual se plantea la necesidad de políticas públicas que fomenten prácticas de ciencia abierta, tales como los datos abiertos, la ciencia ciudadana, la educación abierta las licencias libres, el software y hardware libre y la evaluación abierta, entre otras. Esperamos que esta revista sea un vehículo para estas reflexiones, que se utilicen sus páginas para comunicar y compartir de manera abierta experiencias, procesos y discusiones que profundicen el conocimiento de la ingeniería y su rol social.

Teniendo en cuenta estas ideas, la convocatoria para el primer número de la revista se ideó desde una perspectiva que permitiera tejer una red de académicos y activistas en la región, articular los grupos de investigación, los ejercicios de docencia y por supuesto las iniciativas de extensión o proyección social que se dan en las instituciones académicas de habla hispana. Este llamado se concentró en las personas que anteriormente habían participado en los encuentros de la red, apoyados por los participantes en el Primer Encuentro Colombiano de Ingeniería y Desarrollo Social (2018), en cual lanzamos oficialmente este primera convocatoria en español, así como nuevos grupos de investigadores que están desarrollando actividades desde la ingeniería con un 
claro enfoque de justicia social y paz. Aunque quizás limitada, esta primera invitación a colaborar con este medio pretende generar un espacio de diálogo y discusión que sea permanente entre la comunidad académica. Este llamado espera ser semestral y con esto permitir la participación de los y las investigadoras en nuestras páginas y como no, en el grupo editorial, buscando ser una comunidad mucho más plural, además de un espacio de encuentro con otros saberes.

Para este primer llamado a colaboraciones se han recibido trabajos de Centroamérica y Sudamérica, mayoritariamente de Colombia, donde podemos sugerir una primera hipótesis, con el acuerdo final para la terminación del conflicto entre las FARC-EP y el Gobierno Nacional de Colombia, se abre un espacio para la reflexión del quehacer de la ingeniería en este contexto y su directa relación con la paz con justicia social. Sin embargo, invitamos a la lectura de las contribuciones que este primer volumen posee para entender desde dónde vienen y si todas podrían considerarse como consecuencia de este acuerdo, o por el contrario o como un paso paralelo en la búsqueda de la paz del pueblo Colombiano. A continuación, presentamos los trabajos que los y las autoras nos han confiado para iniciar este primer paso en la larga marcha por compartir el conocimiento libre en las artistas de la ingeniería, la justicia social y la paz.

En esta oportunidad contamos con trabajos en áreas que traslapan la ingeniería, desde comunidades de aprendizaje, pasando por la realización de la universidad con la sociedad, la creación de una asignatura que se basa en el desarrollo de proyectos con comunidades en Colombia, hasta llegar a la puesta en marcha de proyectos de ingeniería en el conflicto armado, y las oportunidades que para la ciencia y la tecnología trae consigo la construcción de paz en Colombia.

Para iniciar, Ángel Gutiérrez, Ernesto Lleras y Julia Díaz (2018) nos presentan un estudio de caso donde se usa el enfoque de comunidades de aprendizaje para generar un espacio de innovación en una organización de servicios públicos. En esta experiencia se establecen relaciones de aprendizaje entre los trabajadores, se asumen roles tanto de aprendices como de mentores y se desarrollan capacidades que permiten fortalecer y proponer nuevas estrategias a la organización. A continuación, Nora Pillard Reynolds, Lain Hunt y William Muños (2018) comparten un texto sobre las características claves para una alianza entre Universidad y actores locales para promover la investigación con características participativas. Para esto, los autores utilizan una serie de herramientas para analizar ejemplos de investigación en el municipio de Waslala en Nicaragua. En este sentido las alianzas entre los actores locales e investigadores son claves en términos de cada una de las actividades en el proceso de indagación. Ahora bien, la mediación, comunicación y diseminación orientadas a diferentes audiencias hacen que los procesos se planteen más allá del proyecto de investigación.

Por su parte, Leonardo León y Angélica Molina (2018) comparten la experiencia de la asignatura Ingenio, Ciencia, Tecnología e Innovación en la Universidad Nacional de Colombia, esta tiene por objetivo de brindar herramientas que permitan desarrollar iniciativas de impacto social en conjunto con comunidades. De esta manera, la asignatura permite incidir de manera pertinente y contextualizada en los territorios donde actúa, priorizando el diálogo de saberes y la co-creación de una solución tecnológica en conjunto con los pobladores. En cuanto a procesos de pos-acuerdo y construcción de paz, Luis Carlos Villegas y Dora Luz Delgado (2018) analizan la actuación de 
empresas que construyen y operan obras de ingeniería en relación con el conflicto armado colombiano. Frente a lo anterior, los autores se enfocan en las empresas que generaron procesos de resistencia, así como de reflexión sobre el conflicto y que aportan a largo plazo para su solución. Para esto, se comparte la iniciativa Programas de Desarrollo y Paz (PDP), los cuales sirven de plataforma para facilitar procesos de empoderamiento comunitario sobre su territorio y disminuir las violaciones de derechos humanos en el mismo.

Finalmente, Christian David Rodríguez y Alexei Ochoa (2018) hacen el análisis desde la perspectiva de la ciencia y tecnología de una nueva estructura epistemológica para el pos-acuerdo en Colombia, después de la firma del acuerdo de paz entre el Gobierno Colombiano y las Fuerzas Armadas Revolucionarias de Colombia - Ejército del Pueblo, con el fin de consolidar la soberanía científica y tecnológica para las regiones colombianas. Desde este punto de vista, los autores proponen las energías renovables y alternativas, la agroecología y la etnobiología como pilares de estas nuevas pedagogías y epistemologías para favorecer la apropiación social de los conocimientos científicos y tecnológicos.

Gracias a estos autores y al trabajo del equipo editorial conformado por Juan David Reina, Andrés Acero, Carolina Menezes y Nicolás Gaitán hacemos posible este primer esfuerzo en el camino de la divulgación científica abierta de la praxis de la ingeniería y sus implicaciones en la justicia social y la paz. Por tanto, invitamos a los y las lectoras para que disfruten de este número inicial y de los futuros volúmenes. Hoy más que nunca la responsabilidad de los y las ingenieras debe ser por la construcción de la paz con justicia social con los pueblos del mundo y el patrimonio cultural y ambiental. En especial dadas las condiciones estructurales que marginalizan a ciertos sectores de la sociedad y al mundo natural, alentadas por la crisis climática y social.

\section{SOBRE LA PORTADA}

La primera portada es una síntesis de objetos recurrentes en las fotos de diversos talleres acerca de la producción de tecnologías locales de bajo costo. La simplicidad de herramientas como la sierra y el taladro es una invitación a tecnologías más democráticas. Sin embargo, la ingeniería no es solo herramientas y tecnologías como también personas y ecosistemas. Además, comprendemos la diversidad como uno de los elementos esenciales para la justicia social y paz evidenciado en las imágenes de la portada.

\section{MINGA EDITORIAL}

Nosotros somos cuatro y cuatro somos nosotros, aunque, para esta encomienda buscamos ser uno. Uno con un propósito común, como la idea de Minga, una relación de trabajo ancestral guiada por el interés colectivo, una celebración entorno a un bien común ¡un compartir!

A continuación, sin olvidarnos de la unidad, nos desagregamos momentáneamente para presentar lo que, en este caso, nos ha traído la unidad. Esperemos que con el tiempo y la amistad los colaboradores de esta Minga seamos más.

Andrés Acero 
Encontrar y crear espacios para desafiar los límites de lo que creemos, lo que hacemos y hasta dónde podemos llegar son mi obsesión. Por eso, trabajo para construir sociedad desde esa frontera invisible que falsamente nos inventamos, la frontera del ingeniero y la comunidad. Me gustan los temas medioambientales también, así como la justicia en todas sus formas y perspectivas.

\section{Carolina M. R. S. Menezes}

Procura la intersección entre tecnología, conocimientos vernaculares e impacto social. Mediante el diseño intenta conectar personas y comunidades para que descubran y exploren su capacidad creativa.

\section{Juan David Reina-Rozo}

Ha caminado varias geografías en aras de conocer prácticas de base de la ciencia y la tecnología contextualizada, creando una praxis alternativa de la ingeniería en conjunto comunidades a nivel local, desde la exploración, la experimentación y el prototipado en común. Así mismo, está interesado en la relación entre la construcción de paz, la tecnociencia y la innovación en los escenarios locales.

\section{Nicolás Gaitán-Albarracín}

Interesado en compartir y aprender, en esta vida, de otras formas de hacer, sentir y pensar la ingeniería, más holísticas y, si esto dice algo, humanas. Me divierten los enfoques de los estudios sociales de la tecnología y me gusta experimentar con el cruce de mundos buscando la posibilidad de crear. Msc en Ingeniería Industrial en la Universidad Nacional de Colombia.

\section{PRIMER LLAMADO A CONTRIBUCIONES}

El primer número de la Revista Internacional de Ingeniería, Justicia Social y Paz decidimos llamarlo Re-encuentros: Creando un espacio integral en la ingeniería, para lograr este cometido expandimos el siguiente llamado:

Queremos compartirles que convocamos a todas las personas que estén relacionadas al mundo de la ingeniería, la justicia social y la paz, para que celebremos la creación de una revista científica internacional dedicada a estas lindes.

El primer número en español de la Revista Internacional de Ingeniería, Justicia Social y Paz lleva por temática los Re-encuentros. Este primer volumen busca poner atención sobre las diversas relaciones entre la Ingeniería, la Justicia Social y la Paz. En este marco, proponemos volver a encontrar los lazos que unen estas tres ideas que alguna vez fueron separadas.

Por tanto, algunas de las reflexiones y acciones que queremos encontrar colectivamente a través de este número son alrededor de:

- ¿Cómo se encuentran estas áreas?

- ¿Qué oportunidades hay? 
- ¿Qué barreras hay?

- ¿Qué experiencias podemos evidenciar en diferentes entornos?

- ¿Cúal podría ser el futuro de estos encuentros?

- ¿Cómo fortalecer esta relación?

- Entre otras...

Para finalizar queremos dar un agradecimiento a todas las personas que hacen esto posible. Que día a día están generando paz con justicia social a través de la ingeniería, la ciencia, tecnología e innovación. Así mismo a contribuir a esta iniciativa que es para nosotros un bien común que deseamos esparcir por muchos lugares del mundo, a pesar de ser en español.

\section{REFERENCIAS}

ESJP Network. (2018). Our commitments. Accedido el día 21 de diciembre de 2018, de http://esjp.org/about-esjp/our-commitments

Gaitán-Albarracín, N., Gutiérrez, A., Lleras, E. \& Molina-Soler, A. (Ed.). (2018). Memorias Primer Coloquio Latinoamericano de Ingeniería para el Desarrollo Social \& Primer Encuentro Colombiano de Ingeniería y Desarrollo Social: Ingeniería, Tecnología y tejido social. Bogotá: ReCIDS.

Gutiérrez, Á., Lleras, E., \& Díaz, J. (2018). Comunidades de Aprendizaje como apoyo a un Sistema de Gestión del Conocimiento y la Innovación. Un estudio de Caso. International Journal of Engineering, Social Justice and Peace, 6(1), 7-25.

Karisma. (2018). Declaración de Panamá de Ciencia Abierta. Accedido el día 20 de diciembre de 2018, https://karisma.org.co/declaraciondepanama/

León, A. L., \& Molina-Soler, A. (2018). Cátedra Ingenio, Ciencia, Tecnología y Sociedad, una experiencia de ingeniería humanitaria. International Journal of Engineering, Social Justice and Peace, 6(1), 39-48.

Reynolds, N. P., Hunt, L., \& Muños, W. (2018). Cuando la universidad de afuera entra: ¿Cuáles son las características claves para promover la investigación participativa? International Journal of Engineering, Social Justice and Peace, 6(1), 26-38.

Rodríguez-Camargo, C., \& Ochoa-Duarte, A. (2018). Caracterización de la Paz en Colombia como escenario de construcción de nuevas pedagogías en ciencia y tecnología. International Journal of Engineering, Social Justice and Peace, 6(1), 68-91.

Villegas, L. C., \& Delgado, D. L. (2018). Proyectos de ingeniería y conflicto armado: Una perspectiva de RSE. International Journal of Engineering, Social Justice and Peace, 6(1), 49-67. 